\title{
Determination of Slope Length and Steepness Factor (LS) For Duruji River Basin
}

\author{
Irma Inashvili ${ }^{1}$, Konstantine Bziava ${ }^{2}$, Irina Denisova ${ }^{3}$, Marine Shogiradze ${ }^{4}$ \\ ${ }^{1}$ Dr., Professor, Georgian Technical University, ORCID: 0000-0002-6202-4580 \\ ${ }^{2}$ Dr., Associate Professor, Georgian Technical University, ORCID: 0000-0003-1237-5224 \\ ${ }^{3}$ Dr., Assistant Professor, Georgian Technical University, ORCID: 0000-0002-3807-0042 \\ ${ }^{4} \mathrm{PhD}$ Student, Georgian Technical University
}

\begin{abstract}
Based on the application of the Revised Universal Soil Loss Equation (RUSLE) and modern GIS technology (ArcGis 10.2.2.), the article presents a method for calculating the erosion potential of the relief (LS) of the Duruji river basin (north-eastern part of Georgia). The most erosion-hazardous areas have been identified, which is approximately $75.1 \%$ of the total area of the Duruji river basin. It has been established that special attention should be paid to a detailed study of the identified erosional areas of the Duruji river basin, taking into account all the influencing factors on soil erosion for the successful design of erosion control measures.
\end{abstract}

KEYWORDS: erosion potential, LS factor, slope length, GIS technology.

\section{INTRODUCTION}

Modelling the process of water erosion of the soil cover is a complex and not fully resolved problem. One of the most important tasks of erosion research is the assessment of soil erosion hazard.

Erosion-hazardous soils are considered where combinations of natural conditions (climate, relief, parent and underlying rocks, precipitation) create the possibility of soil erosion during their agricultural use. The erosion hazard is assessed by the value of the potential washout. Currently, there are a number of models of soil erosion, the implementation of which is partially represented in various software systems [1, 2]. These models are based on dividing the watershed into separate cells of the regular grid and assigning to each cell a set of attributes such as values of: slope, slope length, rain erosion rate, soil erosion rate, etc.

Most of the software tools that fully implement such models are research versions, the methods and algorithms of which require additional analysis and performance evaluation. The effectiveness of the practical use of models is largely determined by the availability of initial information; therefore, when developing modern models of soil erosion, the task is to create a model that requires a minimum of available information.

The aim of this study is the determination of slope length and steepness factor (LS) for Duruji River Basin using the
Revised Universal Soil Loss Equation (RUSLE), GIS technology (ArcGis 10.2.2.) and available Digital Elevation Models (Dem).

\section{STUDY AREA}

The valley of the river Duruji is located in Kvareli municipality (in the north-eastern part of Kakheti, Georgia) (Fig.1.). It is bordered by Tsitelgori and Pokhali ridges, as well as by the main ridge of Ninikastsikhe-Zurgisdze. The Duruji River flows into the valley, the length of which is actually 19.8 kilometres, and the direct line is 14.6 kilometers. The river Duruji is the left tributary of the Alazani and it will be created by joining two Shavi and Tetri Duruji, the first of which starts from the mountain Shavi Klde, and the second from the southern slope of Mount Ninikastsikhe.

Complex geological, geomorphological and hydrometeorological phenomena are formed in the Duruji river basin, the movement of a highly concentrated flow of groundwater in the channel of a river or a ravine is recorded. This is due to rugged relief, strong inclination of slopes and river bed, dynamic development of denudation and erosion processes, intensive snowmelt, runoff from natural or artificial reservoirs, and heavy pouring rain [3]. 


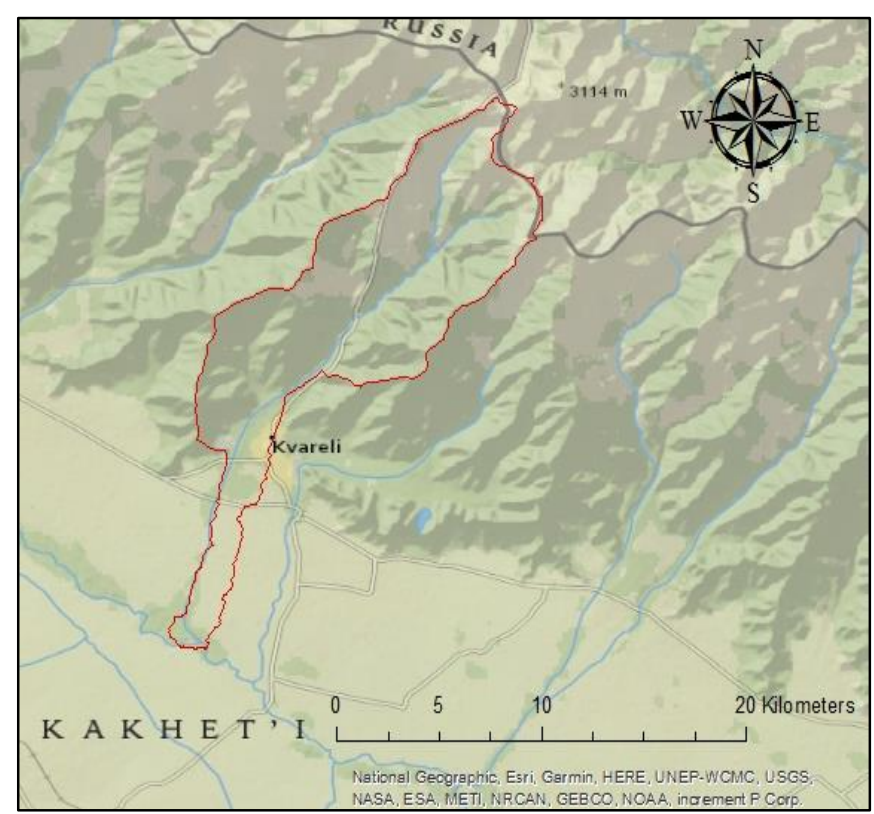

Fig. 1. Layout of Duruji river basin

\section{METHODOLOGY}

The empirical model RUSLE (Revised Universal Soil Loss Equation), developed by Wischmeier and Smith [5] and modified by Renard and Foster [6], is a simple mathematical expression based on five main factors that determine the intensity of water erosion processes, which led to its choice as the initial one in our research. A three-dimensional elevation model was used as the initial data in the study.

The Revised Universal Soil Loss Equation (RUSLE), which developed cooperatively by the U. S. Department of Agriculture (USDA)-Agricultural Research Service (ARS), the USDA-Natural Resources Conservation Service (NRCS), and the Biosystems Engineering and Environmental Science Department of the University of Tennessee, looks like:

$$
A=R \times K \times L \times S \times C \times P
$$

Where: $A$ is the long-term average annual soil loss, tha per year;

$R$ - the rainfall and runoff factor, $M J \times m m /($ ha $\times$ hour $)$;

$K$ - the soil erodibility factor, $t \times h a \times h /(M J \times m m \times h a)$;

$L$ - the slope length factor (dimensionless);

$S$ - the slope steepness factor (dimensionless);

$C$ - the cover-management factor (dimensionless, varying from 0 to 1 );

$P$ - the support practice factor (dimensionless, varying from 0 to 1$)$.

The effectiveness of using the RUSLE model largely depends on the quantitative interpretation of the parameters included in it, where the determination of the LS factor plays the most important role. Topographic factor LS is also known as Relief Erosion Potential.

Calculation of the slope length using a Digital Elevation
Model (DEM) is most problematic in the modelling process of soil erosion. There are several main approaches for determining this parameter using GIS. Most of them are based on the theory of flow rate and the calculation of the flow accumulation as a substitute for the actual length of the slope. The proposed approaches require the implementation and improvement of the functions of hydrological analysis of watersheds in GIS. In our studies, for determination of the topographic factor (LS), the following approach of the RUSLE model was used [4, 5, 6, 7, 8, 9]:

$$
\begin{gathered}
L=\left(\frac{\lambda}{22.13}\right)^{m} \\
m=\frac{F}{(1+F)}, \\
F=\frac{\sin \beta / 0.0896}{3(\sin \beta)^{0.8}+0.56}, \\
L_{(i, j)}=\frac{\left(A_{(i, j)}+D^{2}\right)^{m+1}-A_{(i, j)} x^{m+1} \cdot D^{m \cdot(22.13)^{m}}}{S_{(i, j)}}= \begin{cases}10.8 \sin \beta_{(i, j)}+0.03 & \tan \beta_{(i, j)}<0.09 \\
16.8 \sin \beta_{(i, j)}-0.5 & \tan \beta_{(i, j)} \geq 0.09\end{cases}
\end{gathered}
$$

where $\lambda$ is the slope length (in meters);

$m$ - related to the ratio $\beta$ of the rill to interill erosion; $m$ is equivalent to 0.5 for slopes steeper than $5 \%, 0.4$ - for slopes between $3 \%-4 \%, 0.3$ - for slopes between $1 \%-3 \%$ and 0.2 for slopes less than $1 \% ; m$ approaches 0 when the ratio of rill to interill erosion is close to 0 ;

$A_{(i, j)}$ - the contributing area at the inlet of grid cell $(i, j)$ measured in $\mathrm{m}^{2}$;

$D$ - the grid cell size (meters);

$x$ - the aspect direction of the grid cell $(i, j)$.

In ArcMap, the topographic factor (LS) is calculated based on these expressions (2), (3), (4), (5) and (6) using the Raster Calculator tool. The sequence of computations in ArcMap carried out as follows:

1. $\mathrm{F}=((\operatorname{Sin}(" \%$ Slope.tif\%" * 0.01745) / 0.0896) / $(3 *$ Power(Sin("\%Slope.tif\%" * 0.01745),0.8) + 0.56));

2. $\mathrm{M}=$ "\%Factor_F\%" / (1 + "\%Factor_F\%");

3. $\mathrm{L}=($ Power(("\%Flow_Accumulation.tif\%" + 625), $(" \%$ Factor_M\%" $\quad+\quad 1)) \quad-\quad$ Power ("\%Flow_Accumulation.tif\%",("\%Factor_M\%" + 1))) / (Power(25,("\%Factor_M\%" + 2)) * Power(22.13,"\%Factor_M\%"));

4. $\mathrm{S}=\operatorname{Con}((\operatorname{Tan}(" \%$ Slope.tif\%" * 0.01745) < 0.09),(10.8* $* \operatorname{Sin}(" \%$ Slope.tif\%" * 0.01745) + 0.03),(16.8* $\operatorname{Sin}(" \%$ Slope.tif\%" * 0.01745) - 0.5));

5. LS="\%Factor_L\%" * "\%Factor_S\%".

The Figure 2 illustrates a model for calculating the topographic factor LS (relief erosion potential). 


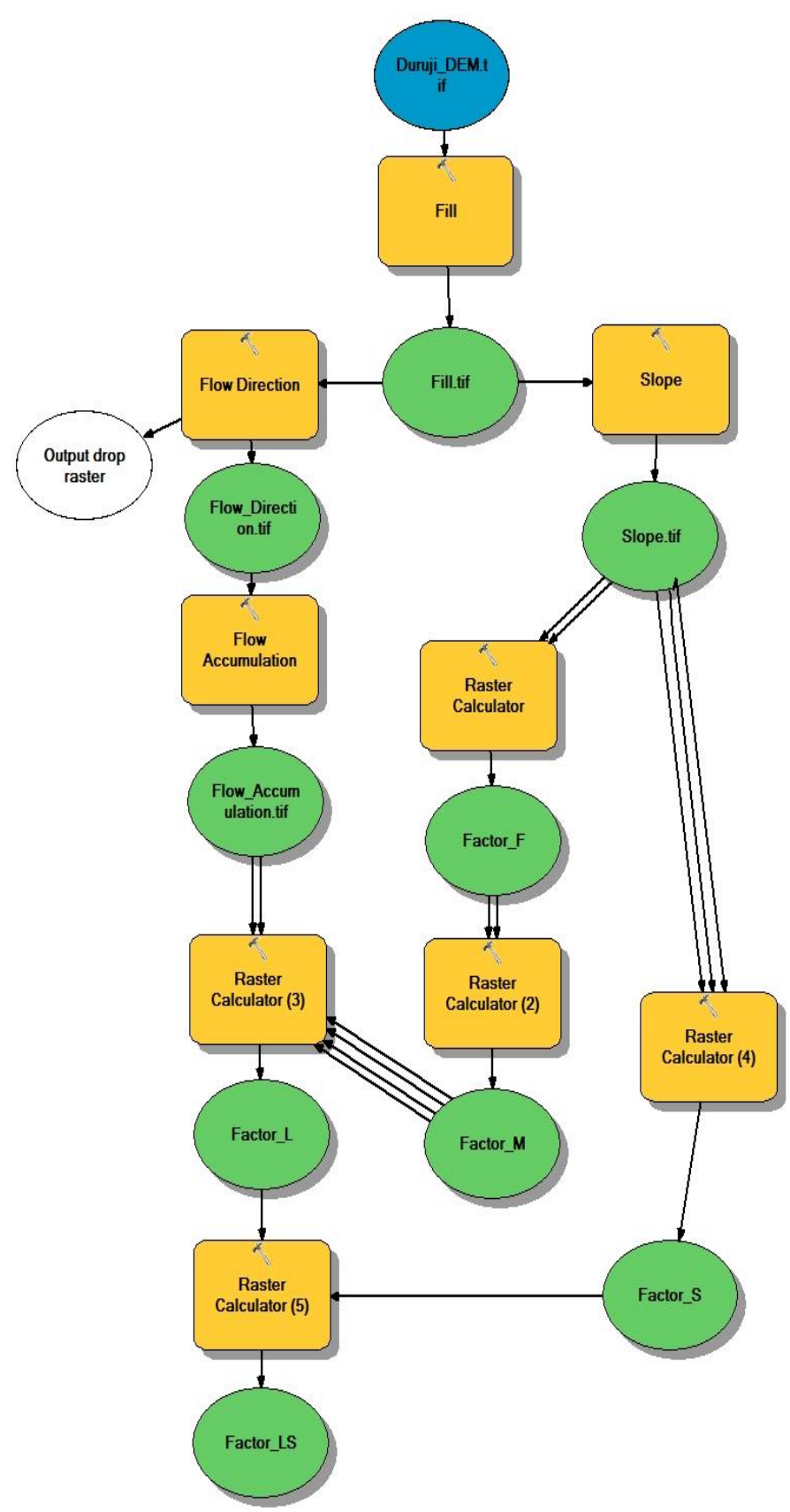

Fig. 2. Model for calculating the topographic factor LS

\section{RESULTS AND DISCUSSION}

Based on the above described calculations, the following results were obtained:

1. Figure 3 shows the calculated data of the surface runoff of the Duruji river basin;

2. Figure 4 - Slope of the Duruji River Basin;

3. Figure 5 - L - slope length factor (dimensionless); S slope steepness factor (dimensionless);

4. Figure 6 - LS topographic factor (relief erosion potential).

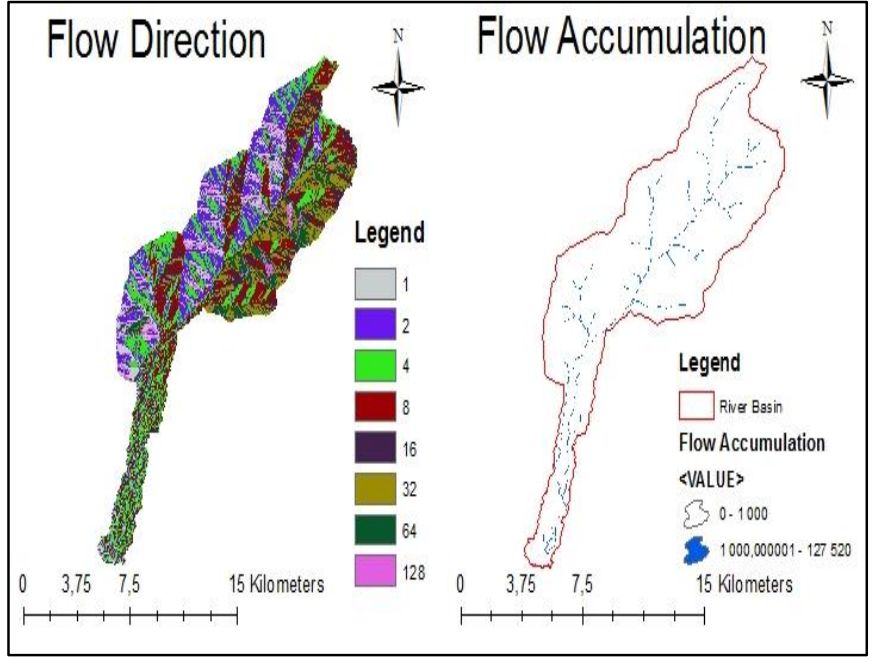

Fig. 3. Flow direction and flow accumulation of Duruji river basin

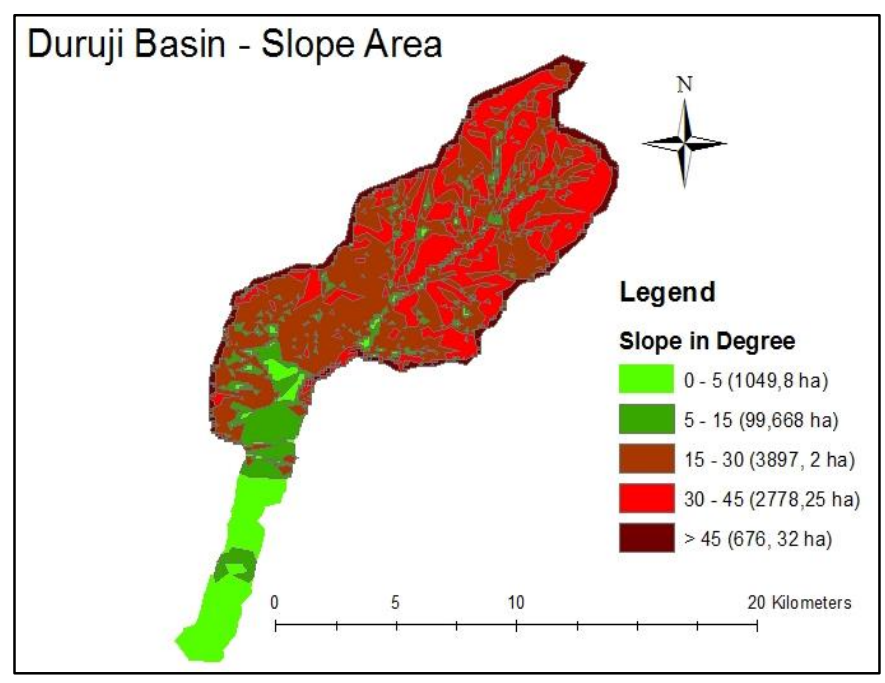

Fig. 4. Slope of the Duruji River Basin

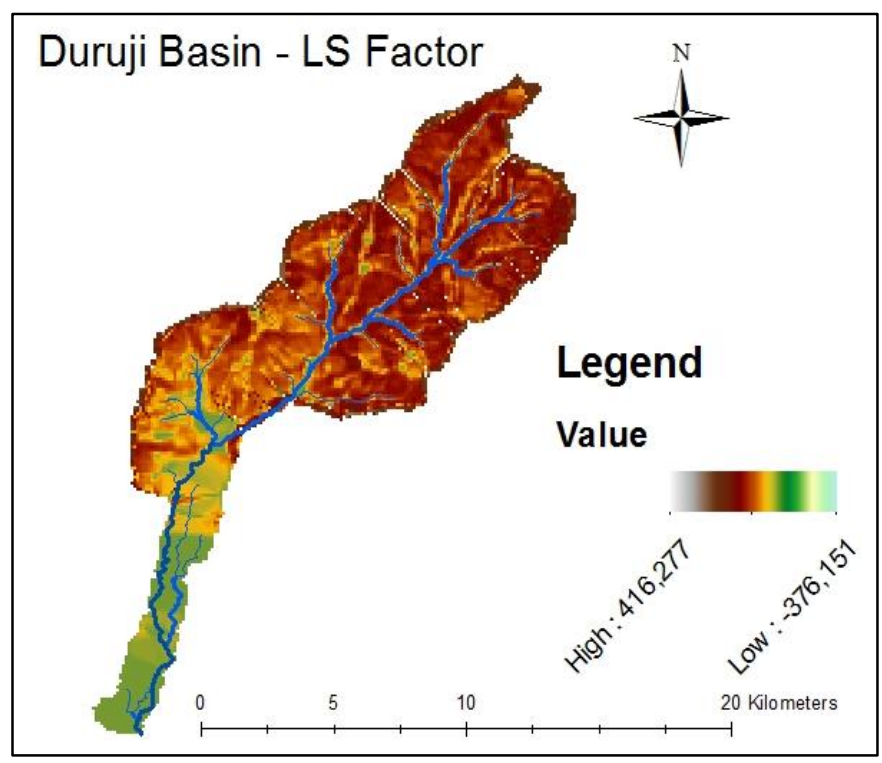

Fig. 5. Topographic factor LS (erosion potential of the relief) 
factor), using ArcGis, classification and calculation of the area of one or another slope were performed. The obtained values are given in Table 1, and to visualize the data, the corresponding graph (Figure 6) of the dependence of the LS factor on the slope is built.

Table 1. The ratio of the area of the Duruji river basin to the slope

\begin{tabular}{|l|l|l|}
\hline$\#$ & Slope (in degrees) & Area (ha) \\
\hline 1 & $<0,1$ & 737.947 \\
\hline 2 & $0,1-0,5$ & 94.702 \\
\hline 3 & $0,5-1$ & 204.55 \\
\hline 4 & $1-2$ & 281.984 \\
\hline 5 & $2-3$ & 284.691 \\
\hline 6 & $3-5$ & 701.603 \\
\hline 7 & $5-10$ & 4628.49 \\
\hline 8 & $>10$ & 2354.01 \\
\hline
\end{tabular}

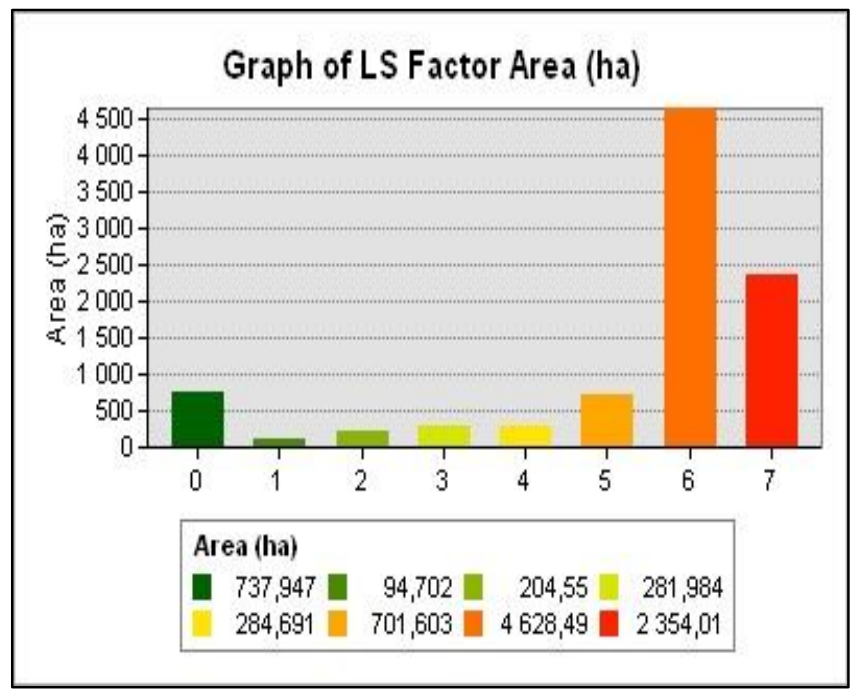

Fig. 6. Graph of LS Factor Area (ha) and factor LS versus slope

\section{CONCLUSIONS}

As a result of the analysis of the studies carried out, the following conclusions were made:

1. The slope of the relief within the basin of the Duruji River varies within a huge range from 0 to $85.35^{\circ}$, and the distribution over the area is as follows: $0-15^{\circ}$ (2054.83 ha); $15-30^{\circ}$ (3891.74 ha); $30-45^{\circ}$ (2778.25 ha); > $45^{\circ}$ (676.32 ha);

2. Analyzing the topographic factor LS (erosion potential of the relief), it was revealed that the minimum value of the factor is LS $=-376.151$ (within the city of Kvareli and water bodies located in the basin), and the maximum reaches 416.277 (in mountainous and foothill areas);

3. The area of the most erosion-hazardous areas is 6982.5 hectares, i.e. $75.1 \%$ of the Duruji river basin.

Based on the foregoing, special attention should be paid to a detailed study of the identified erosional areas of the Duruji
River basin, taking into account all the influencing factors on soil erosion for the successful design of anti-erosion measures.

\section{REFERENCES}

1. Kerzhentsev S. et al. (2006). Modeling the erosion processes in the small watercatchment basin. Institute of Fundamental Problems of Biology, Russian Academy of Sciences, Publisher: NaukaM, 224 p. ISBN-10: 502034205X, ISBN-13: 9785020342057 (in Russian).

2. Gorbacheva E.N. (2011). RUSLE model implementation for estimation intensivity of water erosion processes on Belarusian soil cover. Publisher: "Institute for soil science and agrochemistry", Soil science and agrochemistry №2(47), Minsk, Belarus, pp. 42-51, ISSN 01308475 (in Russian).

3. Supatashvili T. (2014). Evaluation ecological condition of the river Duruji" 4th International Scientific and Technical Conference „Modern Problems of Water Management, Environmental Protection, Architecture and Construction". Tbilisi, Georgia, pp. 231-233. (in Georgian).

4. Panos Panagos, Pasquale Borrelli, and Katrin Meusburger. (2015). A New European Slope Length and Steepness Factor (LS-Factor) for Modelling Soil Erosion by Water. Geosciences 5(2), pp. 117-126.

5. Wischmeier, W., Smith, D. (1978). Predicting Rainfall Erosion Losses: A Guide to Conservation Planning; Agricultural Handbook No. 537; USDA, Science and Education Administration: Hyattsville, MD, USA.

6. Foster G.R., Wischmeier W. (1974). Evaluating irregular slopes for soil loss prediction. Trans. Am. Soc.Agric. Eng. 17, pp. 305-309.

7. McCool D.K., Foster G.R., Mutchler C.K., Meyer L.D. (1989). Revised slope length factor for the Universal Soil Loss Equation. Trans. Am. Soc. Agric. Eng. 32, pp. 1571-1576.

8. Mitasova H., Hofierka, J., Zlocha, M., Iverson, L.R. (1996). Modelling topographic potential for erosion and deposition using GIS. Int. J. Geogr. Inf. Syst. 10, pp. 629-641.

9. Desmet P., Govers G. (1997). Comment on 'Modelling topographic potential for erosion and deposition using GIS'. Int. J. Geogr. Inf. Sci. 11, pp. 603-610. 